\title{
Uterine NK cells: active regulators at the maternal-fetal interface
}

\author{
Ashley Moffett' 1,2 and Francesco Colucci2,3 \\ ${ }^{1}$ Department of Pathology and ${ }^{2}$ Centre for Trophoblast Research, Physiology Building, University of Cambridge, \\ Cambridge, United Kingdom. ${ }^{3}$ Department of Obstetrics and Gynaecology, University of Cambridge School of Clinical Medicine, \\ NIHR Cambridge Biomedical Research Centre, Addenbrooke's Hospital, Cambridge, United Kingdom.
}

\begin{abstract}
Pregnancy presents an immunological conundrum because two genetically different individuals coexist. The maternal lymphocytes at the uterine maternal-fetal interface that can recognize mismatched placental cells are $T$ cells and abundant distinctive uterine NK (uNK) cells. Multiple mechanisms exist that avoid damaging $\mathrm{T}$ cell responses to the fetus, whereas activation of uNK cells is probably physiological. Indeed, genetic epidemiological data suggest that the variability of NK cell receptors and their MHC ligands define pregnancy success; however, exactly how uNK cells function in normal and pathological pregnancy is still unclear, and any therapies aimed at suppressing NK cells must be viewed with caution. Allorecognition of fetal placental cells by uNK cells is emerging as the key maternalfetal immune mechanism that regulates placentation.
\end{abstract}

\section{The maternal-fetal interface in the uterus}

The immunological paradox of pregnancy became a central preoccupation of immunologists after the discovery of acquired immunological tolerance (1). Pregnancy and transplantation were instrumental in the discovery of MHC polymorphisms, since the best natural producers of alloantibodies against HLA molecules are multiparous women (2) and polytransfused individuals (3). Since Medawar's influential essay (4), the focus for immunologists has been how maternal $\mathrm{T}$ cells become tolerant of the fetal allograft. The current state of this field has been summarized in recent scholarly reviews $(5,6)$. We have taken a different approach that arose from studying pregnancy disorders, which affect millions of women and are a persistent global health problem. This view of the maternal immune system arose from considering how placentation evolved in mammals and is centered on the anatomy, physiology, and pathology of the pregnant uterus. We focus on the immune cells present in the pregnant uterine lining, the decidua, dominated by NK cells (known as decidual NK cells or uterine NK [uNK] cells), which are distinct from peripheral blood NK (pbNK) cells (7-9). NK cells have become a focus for clinicians treating women with a history of infertility and recurrent miscarriage, based on the mistaken notion that they are causing reproductive failure by killing the embryo.

The fetal cells in direct contact with the mother in the uterus are trophoblast cells, which are derived from the trophectoderm layer surrounding the blastocyst, sheltering the fetus in its own cocoon $(10,11)$. For immunologists, the distinction between the two fetal cell types - extraembryonic trophoblast cells and cells of the embryo itself - is important. The maternal and fetal circulations do not mix, although transient exchange of cells occurs, particularly during the trauma of delivery. To ensure sufficient delivery of maternal nutrients and oxygen to the placenta, a substantial increase in uterine blood flow is needed for normal fetal growth. This is achieved by invasion of trophoblast cells through the uterine epithelium and into arteries. Maternal blood is thus in direct contact with trophoblast cells (hemochorial placentation). Trophoblast invasion is always accompanied by dramatic changes

Conflict of interest: The authors have declared that no conflict of interest exists. Citation for this article: J Clin Invest. 2014;124(5):1872-1879. doi:10.1172/JCI68107. to the uterine mucosa known as decidualization (Figure 1), which is characterized by differentiation of glandular and stromal elements, as well as increased tortuosity of spiral arteries and loosening of their media (12). Additionally, large numbers of uNK and myelomonocytic cells and smaller numbers of T cells accumulate, particularly around invading trophoblast cells $(11,13)$. Here, we question how two types of lymphoid cells - T cells and NK cells, which are both capable of allorecognition - might recognize and respond to the fetoplacental unit.

\section{T cells in pregnancy}

We discuss here $\mathrm{T}$ cell allorecognition; other aspects of maternal $\mathrm{T}$ cells in pregnancy are discussed in an excellent review (14). The trophoblast cells invading into maternal decidua are allogeneic and thus potential targets for $T$ cells. Tissues grafted from one allogeneic individual to another are always rejected, because the recipient's T cells react against non-self MHC molecules and other proteins, known as minor histocompatibility antigens (15). Maternal T cells are capable of reacting to alloantigens and are not immunologically inert, as shown by the presence of fetal-specific $\mathrm{T}$ cells $(16,17)$ and $\mathrm{T}$ cell-dependent humoral responses specific for the Rhesus D antigen in Rh-negative women (18), or for paternally derived allogeneic HLA molecules in multiparous women (19). A problem in understanding the role of these maternal $\mathrm{T}$ cell responses in pregnancy has been the difficulty in uncoupling those $\mathrm{T}$ cells specific for trophoblast cells (either in the decidua or systemically) from those with fetal somatic cell specificity. Although elegant studies in mice have shown the presence of maternal $T$ cells specific for paternal transgenes (i.e., actin-OVA and actin2W1S; refs. 20,21) or for male antigens (22), the nature of the tissue targeted by maternal effector $T$ cells cannot be defined, since the paternally inherited genes are assumed to be present in both trophoblast cells and fetus. In humans, trophoblast-specific T cells are likely to be HLA-C restricted, as this is the only polymorphic trophoblast HLA class I molecule.

Apart from distinguishing between responses to either trophoblast or fetal cells, whether responses are generated systemically or locally in the decidua is also important. In HLA-C-mismatched pregnancies, decidual $\mathrm{T}$ cells are present that could potentially recognize fetal HLA-C at the maternal-fetal interface (23). In mice, 


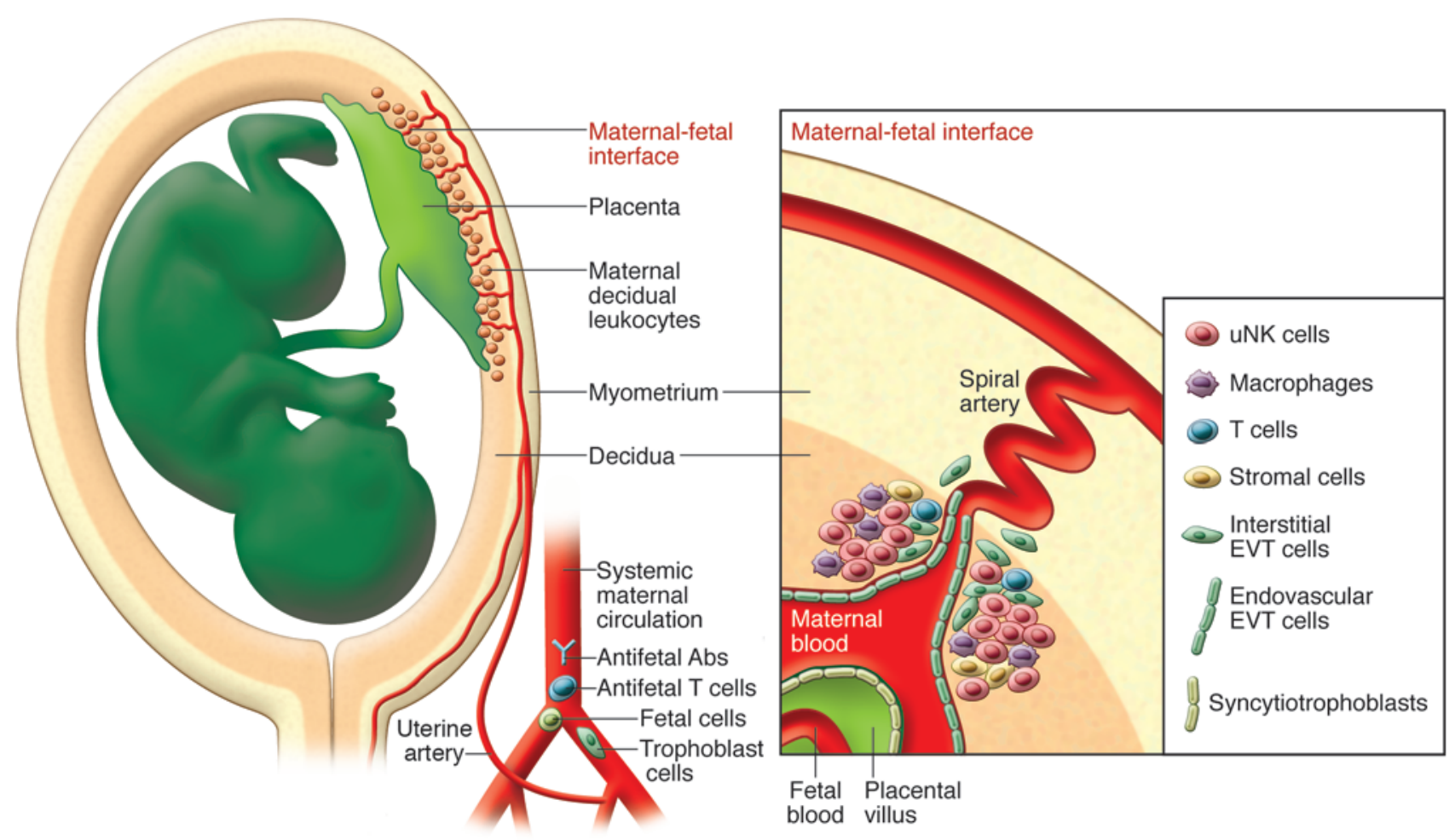

Figure 1

Maternal immune response to fetus and placenta. The maternal immune system does not ignore the fetal allograft. Antibodies specific for paternally inherited Rhesus D antigen and for HLA molecules — or, rarely, T cells specific for mismatched minor histocompatibility antigens — are found in the maternal circulation. However, these T cells do not normally reach the fetus itself, as this is protected by several mechanisms, including the placental barrier. The uterine mucosa is in direct contact with the fetal placenta at the maternal-fetal interface. This is the major site where fetal placental cells (not the embryo proper) are directly in contact with maternal tissues. The decidua is a specialized tissue that is rich in uNK and myeloid cells and also contains maternal T cells, including effector T cells and Tregs. Although it appears clear that uNK cells have receptors that can interact with HLA-C molecules on invasive trophoblast cells at the interface, how effector T cells might interact with the trophoblast cells is unclear. Circulating in the maternal blood are antifetal antibodies and T cells together with fetal cells and trophoblast cells.

there are no data available on specificity of decidual T cells. However, many studies in mice and humans have described mechanisms that favor $\mathrm{T}$ cell tolerance in the decidua: lymphatic drainage enabling decidual APC migration to regional lymph nodes is poor $(24,25)$; decidual APCs express immunoreceptors that bind trophoblast HLA-G molecules, preventing them from being immunogenic $(26,27)$; chemokine genes that attract $T$ cells are epigenetically silenced in decidual stromal cells (28); and cytotoxic $T$ cells in the human decidua express less perforin and granzyme $B$ (29). Other antigen-independent mechanisms include expression of FAS ligand, galectins, and immunosuppressive cytokines such as IL-10 and TGF- $\beta(5,6)$. Questions also remain regarding the mechanisms by which effector $\mathrm{T}$ cells cause fetal loss. Moreover, although Treg depletion leads to fetal demise, indicating that these cells play some role in pregnancy, their specificity and the mechanisms used are unclear and could be due to nonspecific inflammation at the maternal-fetal interface (14).

We conclude that in humans, systemic adaptive immune responses to fetal antigens are generated, but there is no evidence that they ever cause pregnancy failure due to damage to placental trophoblast cells ("rejection" in the popular vernacular). This is, of course, different than death of the fetus caused by, for example, anti-Rhesus antibodies. In mice, this may not be true, as shown by fetal loss in Leishmania infection (30). However, many reports show qualitative changes in human pregnancy, including a definitive recent report studying CTL response to $\mathrm{HCV}$ (31). This supports clinical observations that responses to viruses such as flu and chicken pox $(32,33)$, as well as to autoantigens, differ during pregnancy (34-36). Our conclusion is that responses are deviated during pregnancy toward more vigorous CTL responses, but this seems to have no effect on placental survival or function. Mouse studies suggest that Tregs may prevent the generation of effector $\mathrm{T}$ cells at the maternal-fetal interface (37).

Our focus has now shifted from $\mathrm{T}$ cell tolerance to the innate immune response to the placenta, because of the predominance of uNK and myelomonocytic cells at the site of placentation and the observations that, unlike $T$ cells, there are cognate receptor-ligand interactions whereby uNK cells recognize trophoblast cells.

\section{uNK cells}

The key to successful human pregnancy is the dramatic remodeling of the spiral arteries, with destruction of the media by invading extravillous trophoblast (EVT) cells (38). It is this process that is flawed in the great obstetric syndromes (GOS): preeclampsia, stillbirth, and fetal growth restriction (FGR) (39). Pathological conditions point to a key role for decidua in regulating placenta- 
tion, because when decidua is absent, trophoblast cells invade deeply into the myometrium (placenta percreta). What is it about decidua that normally allows the correct balance between excessive and defective invasion? Because of the allogeneic nature of trophoblast cells, the idea arose that uNK cells perform this balancing act. Epidemiological studies of preeclampsia also point to a role of the immune system, because it is mainly a disorder of first pregnancies with evidence of partner specificity (40). Memory is a key feature of adaptive immunity, and NK cells are now known to share this property (41).

Functionally, NK cells were identified as lymphocytes that were spontaneously cytotoxic to MHC-null target cells (42-45). Unlike pbNK cells, uNK cells are only weakly cytotoxic against standard cancer cell lines (e.g., K562) and do not normally kill trophoblast cells (46-48). This is somewhat of a puzzle, as uNK cells are large lymphocytes with prominent cytoplasmic granules containing perforin, granzymes, and granulysin, which suggests that other, noncytolytic functions of these proteins are important (49-51). Although uNK cells do not normally kill, they might become cytolytic in certain situations, such as CMV infection in which cellular stress is detected by the NKG2D receptor (52).

The origin of uNK cells is still debated, but they do proliferate and differentiate in utero, probably from early NK progenitors recruited from blood $(53,54)$, although there are reports of $\mathrm{CD} 34^{+}$ cells in the human mucosa (55-57). Evidence exists also for recruitment of mature NK cells from the periphery $(55,58,59)$, and in mice, adrenomedullin secreted by trophoblast cells also recruits uNK cells (60). Thus, several pathways are possible. For example, subsets of murine uNK cells have different origins (50), and tissueresident endometrial $\mathrm{NK}(\mathrm{eNK})$ cells in women may contribute to the pool of uNK cells present during pregnancy (61).

The likely function of uNK cells is to cooperate with trophoblast cells to guarantee correct arterial remodeling $(11,62,63)$, ensuring the supply line to the growing fetus. IFN- $\gamma$ production in mice is a key factor for vascular remodeling (64). In contrast, human uNK cells do not produce IFN- $\gamma$ in abundance; thus, both assays commonly used for pbNK cells (cytotoxicity and IFN- $\gamma$ production) are uninformative (65). Human uNK cells are confined to the mucosa, endometrium, and decidua. In mice, they first accumulate in the decidua basalis (from gestational day 6.5), but subsequently are found in the myometrium around the spiral artery (around gestational day 8.5-13.5) (66). Remodeling of the spiral arteries is the essential tissue modification in both species, but the processes are not identical. Human uNK cells initially cause medial loosening as part of the decidualization process (67). After implantation, surrounding EVT cells destroy the smooth muscle media of the artery (fibrinoid change), followed by replacement of the endothelium by endovascular trophoblast cells $(38,68)$. In mice, there is little trophoblast endovascular migration, and the arterial media is modified mainly as a result of direct infiltration by uNK cells (63). A range of angiogenic factors is produced by uNK cells in both species, and these also likely affect vascular stability and function (69).

\section{NK cell allorecognition in transplantation and pregnancy}

Our hypothesis is that correct arterial transformation depends on allorecognition of trophoblast cells by uNK cells, and this determines successful placentation and fetal development $(62,64$, 69-71). uNK cells express a range of NK receptors (NKRs) that recognize adhesion molecules, stress signals (many of which are



\section{Figure 2}

NK cell education and recognition of allogeneic paternal MHC molecules on trophoblast cells. Individuals inherit one KIR haplotype on chromosome 19 from each parent. Each haplotype contains 7-15 genes (only a few are depicted here for clarity). During NK cell differentiation, KIR genes are expressed in developing NK cells. Each NK cell expresses 0-5 KIRs. Some of the KIRs bind to self MHC molecules and educate NK cells to be tolerant of self and also to react to the absence of self. Allogeneic, paternal MHC molecules on the trophoblast cell can interact with some KIRs on the UNK cell; however, it is not known whether this new interaction educates uNK cells or if the uNK cells recognize the paternal, allogeneic MHC molecule as foreign, generating an alloresponse.

still unknown), and MHC class I ligands (8, 65, 72, 73). Therefore, uNK cells will respond to a wide variety of signals, either induced by the hormonal changes of pregnancy or expressed by trophoblast cells, including allogeneic MHC molecules. The latter are the most variable ligands for the NKRs, some of which are also highly diverse and differ among individuals. Thus, maternal NKRs and MHC ligands in both fetus and mother enable each pregnancy to be subtly different (71).

Each individual inherits two sets of variable NKR genes, one on each chromosome. These are the family of killer cell Ig-like receptors (KIRs), part of the leukocyte receptor complex (LRC) on human chromosome 19, and the Ly49 family within the NK complex on mouse chromosome $6(71)$. KIR haplotypes are defined as either $A$ or $B$. KIR $A$ haplotypes consist of 7 genes, of which only one is a potential activating receptor. KIR $B$ haplotypes are more variable (up to 12 genes), and the extra genes are mostly activating (71). Developing NK cells express $0-5$ inhibitory or activating NKRs; some will bind to self and others to non-self MHC molecules (Figure 2). Inhibitory NKRs that bind self MHC molecules educate NK cells to be tolerant of self and to respond to the lack of these self MHC molecules. Moreover, NK cells constantly tune their activation threshold to the MHC environment in which they operate, a process likened to a rheostat (74).

The presence of allogeneic tissue exposes an individual's immune system to a different set of MHC molecules. TCRs are generated by random somatic gene rearrangement, resulting in $\mathrm{T}$ cells with 


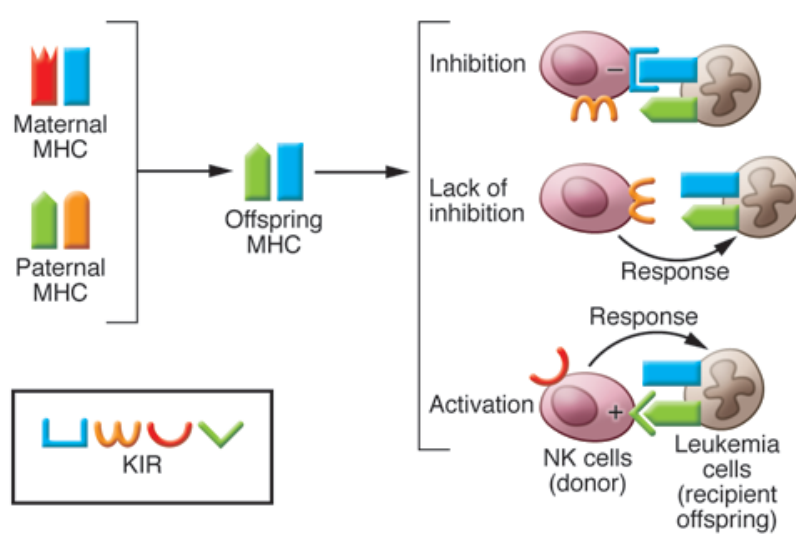

Figure 3

Haploidentical bone marrow transplantation has parallels with maternal allorecognition. Children inherit one MHC haplotype from each parent. In haploidentical bone marrow transplantation, T cell-depleted donor cells from one parent are transferred to a recipient child. In this example, the recipient child has leukemia, the mother is the donor, and her NK cells express a set of KIRs (blue) that bind and are inhibited by MHC molecules on the child's leukemic cells. Other donor uNK cells expressing KIRs (yellow) that do not bind the child's MHC molecules are not inhibited and will destroy the cancer cells. A third group of donor NK cells expresses activating KIRs (green), which, upon binding to the child's MHC molecules, are activated to destroy leukemic cells. In the latter two situations, donor NK cells also destroy the patient's normal hematopoietic cells, including the APCs, and this contributes to preventing graft-versus-host disease caused by residual donor maternal $T$ cells. These three types of interactions are equivalent to the situation between KIRs expressed by maternal UNK cells (donor) and MHC molecules on fetal trophoblast cells (recipient).

TCRs that can recognize allogeneic MHC molecules. After the discovery of KIRs, it was quickly realized that there were abundant $\mathrm{pbNK}$ cells expressing receptors for non-self HLA class I molecules (75). Thus, NK cells represent another class of lymphocytes capable of allorecognition, but this is mediated by germline encoded receptors. Generation of these allospecific KIRs that discern paternally derived trophoblast MHC molecules may have been driven by selective pressure for reproductive success (71). Indeed, the intimate contact between maternal immune and trophoblast cells in pregnancy is the only natural situation in mammals in which allogeneic cells breach epithelial boundaries and come into direct contact (Figure 1). In invertebrates, NK-like allorecognition operates to determine whether fusion of individual colonial forms occur, a situation that has resonance with the demarcation of the maternal-fetal interface (76).

In inbred mice, although solid organs grafted from either of the two genetically distinct parents to F1 hybrid offspring are always accepted (due to $\mathrm{T}$ cell tolerance of the shared MHC haplotype between offspring and both parents), bone marrow transplantation (BMT) violates this law. Hybrid offspring reject marrow grafted from either parent, even after ablation of T cells. This phenomenon (hybrid resistance) was observed before the discovery of NK cells (77), which were subsequently identified as the cells sensing the absence of one set of parental MHC molecules $(78,79)$. Hybrid resistance is now an important in vivo assay by which to study NK cell allorecognition and also provides a conceptual framework for haploidentical BMT, in which allorecognition operates from donor to host. Haploidentical BMT is now used as an alternative strategy when no MHC-matched donors for leukemia patients can be found; it is also beneficial in preventing leukemia relapse (80). Because all individuals have potential haploidentical donors (a parent or a sibling), donors can be easily found. Mismatch between inhibitory NKR on donor NK cells and recipient HLA is generally present, so that some donor NK cells are not inhibited by the recipient's HLA and destroy cancer cells (Figure 3 and ref. 81). This situation has obvious parallels with pregnancy, in which the uNK cell may sense the absence of noninherited maternal self MHC molecules on the placental semi-allograft. By extension, uNK cells may also detect the inherited paternal allogeneic MHC molecule and be educated, inhibited, or activated, depending on the nature of the interaction between the NKR and that MHC.

\section{Expression of trophoblast cell MHC molecules and NKRs at the maternal-fetal interface}

The first steps in testing this theoretical framework were to study expression of MHC molecules on trophoblast cells and NKRs on uNK cells. Villous cytotrophoblast cells and overlying syncytium in contact with maternal blood in the intervillous space are HLA null (82). In contrast, the EVT cells that infiltrate deeply into the uterine wall express a unique set of MHC molecules, including nonclassical HLA-E and -G (27). These are oligomorphic, meaning they will deliver an invariant signal to maternal immune cells. HLA-C molecules are also expressed by EVT cells (83), are polymorphic, and are the dominant ligands for KIRs (71). Thus, both maternal NKR (KIRs) and fetal ligands (HLA-C molecules) are variable and specific to a particular pregnancy. These interactions could educate NK cells or inhibit/activate them, depending on the nature of the mother's KIRs. The frequency of uNK cells expressing KIRs specific for two groups of HLA-C allotypes (C1 or C2) increases in early gestation in uNK cells compared with pbNK cells from the same woman (84-86). Thus, the uNK cell KIR repertoire is skewed toward HLA-C recognition in pregnancy, but this is not a feature of NK cells in the nonpregnant cycle (87).

We have assessed the pattern of trophoblast cell MHC expression in C57BL/ 6 mice by flow cytometry on trophoblast cells differentiated in vitro from trophoblast stem cells and by microscopy on explants of implantation sites at gestational day 8.5. Only $\mathrm{H}-2 \mathrm{~K}$ and not $\mathrm{H}-2 \mathrm{D}$ is expressed and, in contrast to human trophoblast cells, nonclassical MHC molecules are not expressed (88). More recently, we have found that H-2D is expressed by trophoblast cells in BALB/c mice (89); therefore, the pattern of MHC expression may be strain specific. Murine uNK cell subsets are complex in terms of surface markers or effector functions, but, similar to humans, the NKR repertoire of at least one subset is unlike systemic NK cells $(50,90,91)$.

\section{Immunogenetics of reproduction}

Both NKRs and their MHC ligands are highly diverse and encoded by gene complexes on separate chromosomes, thus segregating independently (71). In each pregnancy, therefore, the mother will carry a set of KIRs that will respond to the HLA-C of that particular fetus, with EVT cells expressing both maternal self and paternal non-self HLA-C allotypes (92). Inherent difficulties in investigating uNK cell function in humans include ethical considerations, difficulty of obtaining tissue in early pregnancy, paucity of human trophoblast cell lines with HLA profiles similar to those of normal EVT cells, and lack of good functional uNK cell readouts. A variety 
of approaches is needed: first, genetic studies of maternal KIR-fetal HLA-C combinations in normal and pathological pregnancies have pinpointed the KIR and HLA-C genes that confer both risk and protection for preeclampsia and the other GOS. Second, functional studies using human uNK cells ex vivo are beginning to shed light on how the genetic findings translate into function at the site of placentation (86). Finally, informed by these results, mouse models can be used to mimic the human situation and interrogate how a given NKR-MHC interaction affects pregnancy outcome $(88,89)$.

A consistent finding from genetic studies is that women affected by preeclampsia and other GOS have an increased frequency of two KIR A haplotypes (KIR AA genotype) in combination with a paternally derived $H L A-C 2$ group in the fetus (93-95). The protective genes on the KIR $B$ haplotype in Europeans are found in the telomeric region in which the activating KIR for HLA-C2 (KIR2DS1) is located. These findings suggest that placentation is defective when there is a very strong inhibitory signal to uNK cells mediated via the KIR A haplotype gene, KIR2DL1, which has high affinity for HLA-C2 ligands. Protection from preeclampsia is likely to be mediated by the counterbalancing activating KIR2DS1, which also binds HLA-C2. Thus, depending on the particular KIRHLA-C interactions, levels of chemokines or cytokines secreted by uNK cells will vary and in turn modify trophoblast cell invasion (62). Furthermore, uNK cells expressing KIR2DS1 are specifically activated by coculture with HLA-C2 ${ }^{+}$target cells to produce a range of soluble products, including GM-CSF, which enhances trophoblast cell migration in vitro (86).

Mouse studies allowing for specific combinations of maternal NKRs and paternal MHC molecules in otherwise genetically identical parents show that uNK cells sense the presence of paternal MHC molecules $(89,91)$, and the mismatch between parental MHC molecules has an effect on spiral artery modification and eventually on fetal growth, confirming that certain combinations of maternal NKRs and paternal MHC molecules influence placentation (88). A mating strategy to mimic the human situation of strong inhibition of maternal uNK cells shows that the introduction of a single MHC class I molecule that engages large numbers of inhibitory receptors impedes fetal growth (89).

\section{NK cells and fertility clinics}

The evidence points to important physiological roles for uNK cells in healthy placentation and for their dysfunction in pregnancy disorders. The nature of uNK cell "dysfunction" is unclear, but an appropriate level of NK cell activation seems essential for allocating maternal and fetal resources fairly. Despite this, women are now being given a range of therapies to suppress their NK cells (96). This is based on a poorly formulated supposition that there is a correlation between excessive number or activity of NK cells and adverse reproductive outcome. Specifically, if blood tests for NK cell activity or cell numbers are deemed high, women are given a range of therapies, including prednisolone, intravenous Ig, intralipid, and TNF- $\alpha$-blocking biologicals $(97,98)$. Use of these treatments is based on a misunderstanding of the basic science (as the right degree of activation, rather than inhibition, of uNK cells is needed), and they could potentially have serious side effects (96, 99-101). pbNK cells are quite different from uNK cells in activity, phenotype, function, and morphology $(8,9)$, so results from blood tests will be of little relevance (102). Furthermore, the normal range for pbNK cells is very wide, with no discernible effect on an individual's health at the extremes of the range (42). Indeed,
NK cells are not routinely measured in other clinical contexts, apart from the diagnosis of leukemias.

More recently, commercial tests for quantifying numbers of eNK cells in the luteal phase have been introduced, and steroid therapy is prescribed to those women with "high" levels $(97,103,104)$. How numbers of mucosal NK cells might relate to their functions is not clear, particularly as there is a day-to-day increase during the luteal phase due to uNK cell proliferation. Some clinics are even prescribing G-CSF to women on the basis of these results $(105,106)$. Although the evidence is accumulating that uNK cells regulate placentation, how they do so is still essentially unknown. To summarize, all the available data suggest that uNK cells need to be activated rather than suppressed, and it is inappropriate to use therapies aimed at altering uNK cell function until more is known.

\section{Future directions}

It is clear that, despite some exciting avenues of research, there is some way to go before research on uNK cells can be translated into therapies for couples with reproductive problems including recurrent miscarriage, preeclampsia, and infertility. Indeed, two systematic recent reviews of the literature also caution against the use of any adjuvant therapies aimed at suppressing NK cells $(107,108)$. Our genetic findings on KIR-HLA-C variants in preeclampsia and the other GOS must still be regarded as preliminary, as they have not been repeated by other investigators in European or other populations. Other reports on KIRs in miscarriage are contradictory; we have summarized the reasons for this controversy previously (109). No genetic studies have been carried out in cohorts of infertile women or those with in vitro fertilization failure; it is not certain whether uNK cells will influence the earliest stage of implantation when the blastocyst penetrates the uterine epithelium. With these caveats, it is certainly premature to introduce KIR and HLA-C typing into the reproductive clinics, although this is now occurring in a piecemeal manner $(98,110)$.

The GOS are obviously multifactorial, subject to contributions from other environmental and genetic risk factors. Indeed, the KIR AA genotype that confers risk occurs in approximately $30 \%$ of Europeans, yet not all these women have problems in pregnancy. It may be that as the KIR $A$ haplotype is polymorphic, in-depth analysis at the allelic level of KIR2DL1, the inhibitory KIR binding HLA-C2, is needed. KIR2DL1 has 4 alleles in European populations (and many more in other groups, particularly Africans; ref. 111), which differ in binding affinities to individual HLA-C2 allotypes. Typing of individual fetal HLA-C alleles will also be required, in addition to the $C 1 / C 2$ division (112). If the risky KIR AA genotype can be better defined in the future, it might eventually become possible to inform couples whether there is a possibility of avoiding interactions with certain paternal HLA-C2 alleles. One scenario is already of concern: surrogate mothers, to whom an egg is donated from another woman, have a high incidence of all forms of hypertensive disorders in pregnancy (113). In these pregnancies, both fetal HLA-C alleles are non-self, and if both are $H L A-C 2$, they would provide an unnaturally strong inhibitory signal to uNK cells in surrogate mothers who carry the risky KIR AA genotype.

\section{Conclusions}

We have concentrated here on the dominant population in decidua, uNK cells. It will be important to define the relative role of other decidual leukocytes (macrophages, dendritic cells, effector 
T cells, and Tregs) and how they influence each other. For example, Tregs suppress not only effector T cells, but also NK cells $(114,115)$. NK cells in turn modulate adaptive responses in mice (116) and, together with myelomonocytic cells, induce Tregs in human decidua (117).

There are many challenges to understanding how the genetic diversity of NKR-MHC interactions affects reproduction. Prospective genetic studies of large numbers of first pregnancies with information on possible biomarkers and uterine artery Doppler measurements will be required to understand this relationship. More detailed genetic analysis for both KIR and HLA-C at the allele level is essential. There is still little understanding of how the repertoire of KIR expression is determined on uNK cells and of the effect of the maternal HLA-C group. The granules present in uNK cells may hold a key to their function, and measurements at the single-cell level in response to defined targets may illuminate novel secreted proteins that can affect arteries. A major stumbling block is the lack of reliable in vitro models for human trophoblast biology, particularly trophoblast stem cell lines. Dissecting the underlying interactions among uNK cells, arteries, and trophoblast cells is particularly challenging because of the potential differences between mouse and human placentation and the rapid changes that characterize the uterine microenvironment during early pregnancy. Murine models will nevertheless be useful if particular receptor/ligand pairs are set up in informa- tive matings (89). In vivo imaging of the vasculature, placental development, and fetal growth can be directly visualized in these systems in the future. Despite these difficulties, a new concept is emerging that the uterine immune system uses NK cell allorecognition to regulate placentation and define the territorial demarcation between two individuals, the mother and her fetus.

\section{Acknowledgments}

We are grateful to Gordon Smith and Jens Kieckbusch for critically reading the manuscript. We acknowledge support from the Wellcome Trust (090108/Z/09/Z; 085992/Z/08/Z), British Heart Foundation (PG/09/077/27964; FS/12/4/29254), Medical Research Council (G0900101/1), Centre for Trophoblast Research, University of Cambridge, and King's College, Cambridge.

Address correspondence to: Ashley Moffett, Department of Pathology, University of Cambridge, Tennis Court Road, Cambridge CB2 1QP, United Kingdom. Phone: 44.1223.333727; Fax: 44.1223.765065; E-mail: am485@cam.ac.uk. Or to: Francesco Colucci, Department of Obstetrics and Gynaecology, University of Cambridge School of Clinical Medicine, NIHR Cambridge Biomedical Research Centre, Addenbrooke's Hospital, Box 111, Hills Road, Cambridge CB2 0SP, United Kingdom. Phone: 44.1223.763889; Fax: 44.1223.215327; E-mail: fc287@medschl.cam.ac.uk.
1. Billingham RE, Brent L, Medawar PB. Actively acquired tolerance of foreign cells. Nature. 1953;172(4379):603-606.

2. Van Rood JJ, Eernisse JG, Van Leeuwen A. Leucocyte antibodies in sera from pregnant women. Nature. 1958;181(4625):1735-1736.

3. Dausset J. [Iso-leuko-antibodies]. Acta Haematol. 1958;20(1-4):156-66.

4. Medawar PB. Some immunological and endocrinological problems raised by the evolution of viviparity in vertebrates. Sym Soc Exp Biol. 1953;7:320-338.

5. Erlebacher A. Immunology of the maternal-fetal interface. Annu Rev Immunol. 2013;31:387-411.

6. Erlebacher A. Mechanisms of T cell tolerance towards the allogeneic fetus. Nat Rev Immunol. 2013;13(1):23-33.

7. Bulmer JN, Williams PJ, Lash GE. Immune cells in the placental bed. Int J Dev Biol. 2010; 54(2-3):281-294.

8. Koopman LA, et al. Human decidual natural killer cells are a unique NK cell subset with immunomodulatory potential. J Exp Med 2003;198(8):1201-1212.

9. Moffett-King A. Natural killer cells and pregnancy. Nat Rev Immunol. 2002;2(9):656-663.

10. Carter AM, Mess A. Evolution of the placenta in eutherian mammals. Placenta. 2007;28(4):259-262.

11. Moffett A, Loke C. Immunology of placentation in eutherian mammals. Nat Rev Immunol. 2006;6(8):584-594.

12. Ramathal CY, Bagchi IC, Taylor RN, Bagchi MK. Endometrial decidualization: of mice and men. Semin Reprod Med. 2010;28(1):17-26.

13. Helige C, et al. Distribution of decidual natural killer cells and macrophages in the neighbourhood of the trophoblast invasion front: a quantitative evaluation. Hum Reprod. 2014;29(1):8-17.

14. Nancy P, Erlebacher A. T cell behavior at the maternal-fetal interface. Int J Dev Biol. 2014; In press.

15. Rogers NJ, Lechler RI. Allorecognition. Am J Transplant. 2001;1(2):97-102.

16. James E, Chai JG, Dewchand H, Macchiarulo E, Dazzi F, Simpson E. Multiparity induces priming to male-specific minor histocompatibility antigen, HY, in mice and humans. Blood. 2003;102(1):388-393.

17. Lissauer D, Piper K, Goodyear O, Kilby MD, Moss
PA. Fetal-specific CD8+ cytotoxic T cell responses develop during normal human pregnancy and exhibit broad functional capacity. J Immunol. 2012; 189(2):1072-1080.

18. Clarke CA, Finn R, Lehane D, McConnell RB, Sheppard PM, Woodrow JC. Dose of anti-D $\gamma$-globulin in prevention of Rh-haemolytic disease of the newborn. Br Med J. 1966;1(5481):213-214.

19. van Kampen CA, Versteeg-vd Voort Maarschalk MF, Langerak-Langerak J, Roelen DL, Claas FH. Kinetics of the pregnancy-induced humoral and cellular immune response against the paternal HLA class I antigens of the child. Hum Immunol. 2002;63(6):452-458.

20. Erlebacher A, Vencato D, Price KA, Zhang D, Glimcher LH. Constraints in antigen presentation severely restrict $\mathrm{T}$ cell recognition of the allogeneic fetus. J Clin Invest. 2007;117(5):1399-1411.

21. Rowe JH, Ertelt JM, Xin L, Way SS. Pregnancy imprints regulatory memory that sustains anergy to fetal antigen. Nature. 2012;490(7418):102-106.

22. Kahn DA, Baltimore D. Pregnancy induces a fetal antigen-specific maternal $\mathrm{T}$ regulatory cell response that contributes to tolerance. Proc Natl Acad Sci U S A. 2010;107(20):9299-9304.

23. Tilburgs T, et al. Fetal-maternal HLA-C mismatch is associated with decidual $\mathrm{T}$ cell activation and induction of functional $\mathrm{T}$ regulatory cells. J Reprod Immunol. 2009;82(2):148-157.

24. Collins MK, Tay CS, Erlebacher A. Dendritic cell entrapment within the pregnant uterus inhibits immune surveillance of the maternal/fetal interface in mice. J Clin Invest. 2009;119(7):2062-2073.

25 . Volchek M, et al. Lymphatics in the human endometrium disappear during decidualization. Hum Reprod. 2010;25(10):2455-2464.

26. Apps R, Gardner L, Sharkey AM, Holmes N, Moffett A. A homodimeric complex of HLA-G on normal trophoblast cells modulates antigenpresenting cells via LILRB1. Eur J Immunol. 2007; 37(7):1924-1937.

27. Apps R, Gardner L, Moffett A. A critical look at HLA-G. Trends Immunol. 2008;29(7):313-321.

28. Nancy P, Tagliani E, Tay CS, Asp P, Levy DE, Erlebacher A. Chemokine gene silencing in decidual stromal cells limits $\mathrm{T}$ cell access to the maternalfetal interface. Science. 2012;336(6086):1317-1321.

29. Tilburgs $T$, et al. Human decidual tissue contains differentiated CD8+ effector-memory $\mathrm{T}$ cells with unique properties. J Immunol. 2010; 185(7):4470-4477.

30. Krishnan L, Guilbert LJ, Wegmann TG, Belosevic M, Mosmann TR. T helper 1 response against Leishmania major in pregnant $\mathrm{C} 57 \mathrm{BL} / 6$ mice increases implantation failure and fetal resorptions. Correlation with increased IFN-gamma and TNF and reduced IL-10 production by placental cells. Jimmunol. 1996;156(2):653-662.

31. Honegger JR, et al. Loss of immune escape mutations during persistent $\mathrm{HCV}$ infection in pregnancy enhances replication of vertically transmitted viruses. Nat Med. 2013;19(11):1529-1533.

32. Lamont RF, et al. Varicella-zoster virus (chickenpox) infection in pregnancy. BJOG. 2011; 118(10):1155-1162.

33. Louie JK, Acosta M, Jamieson DJ, Honein MA, California Pandemic Working Group. Severe 2009 H1N1 influenza in pregnant and postpartum women in California. NEngl J Med. 2010;362(1):27-35.

34. Baer AN, Witter FR, Petri M. Lupus and pregnancy. Obstet Gynecol Surv. 2011;66(10):639-653.

35 . Hughes GC. Progesterone and autoimmune disease. Autoimmun Rev. 2012;11(6-7):A502-A514.

36. Neuteboom RF, et al. Pregnancy in multiple sclerosis: clinical and self-report scales. J Neurol. 2012; 259(2):311-317.

37. Rowe JH, Ertelt JM, Aguilera MN, Farrar MA, Way SS. Foxp3(+) regulatory T cell expansion required for sustaining pregnancy compromises host defense against prenatal bacterial pathogens. Cell Host Microbe. 2011;10(1):54-64.

38. Pijnenborg R, Vercruysse L, Hanssens M. The uterine spiral arteries in human pregnancy: facts and controversies. Placenta. 2006;27(9-10):939-58.

39. Brosens I, Pijnenborg R, Vercruysse L, Romero R. The "Great Obstetrical Syndromes" are associated with disorders of deep placentation. Am J Obstet Gynecol. 2011;204(3):193-201.

40. Wikstrom AK, Gunnarsdottir J, Cnattingius S. The paternal role in pre-eclampsia and giving birth to a 
small for gestational age infant; a population-based cohort study. BMJ Open. 2012;2(4):pii:e001178.

41. Sun JC, Lopez-Verges S, Kim CC, DeRisi JL, Lanier LL. NK cells and immune "memory". I Immunol. 2011;186(4):1891-1897.

42. Caligiuri MA. Human natural killer cells. Blood. 2008;112(3):461-469.

43. Herberman RB, Nunn ME, Lavrin DH. Natural cytotoxic reactivity of mouse lymphoid cells against syngeneic acid allogeneic tumors. I. Distribution of reactivity and specificity. Int J Cancer. 1975;16(2):216-229.

44. Kiessling R, Klein E, Wigzell H. "Natural” killer cells in the mouse. I. Cytotoxic cells with specificity for mouse Moloney leukemia cells. Specificity and distribution according to genotype. Eur I Immunol. 1975;5(2):112-117

45. Timonen T, Ortaldo JR, Herberman RB. Characteristics of human large granular lymphocytes and relationship to natural killer and K cells. J Exp Med 1981;153(3):569-582

46. Ferry BL, Starkey PM, Sargent IL, Watt GM, Jackson M, Redman CW. Cell populations in the human early pregnancy decidua: natural killer activity and response to interleukin-2 of CD56positive large granular lymphocytes. Immunology. 1990;70(4):446-452.

47. King A, Birkby C, Loke YW. Early human decidual cells exhibit NK activity against the K562 cell line but not against first trimester trophoblast. Cell Immunol. 1989;118(2):337-344.

48. Ritson A, Bulmer JN. Isolation and functional studies of granulated lymphocytes in first trimester human decidua. Clin Exp Immunol. 1989; 77(2):263-268

49. King A, Wooding P, Gardner L, Loke YW. Expression of perforin, granzyme A and TIA- 1 by human uterine CD56+ NK cells implies they are activated and capable of effector functions. Hum Reprod. 1993;8(12):2061-2067.

50. Chen $Z$, et al. DBA-lectin reactivity defines mouse uterine natural killer cell subsets with biased gene expression. Biol Reprod. 2012;87(4):81.

51. Vujaklija DV, et al. First trimester pregnancy decidual natural killer cells contain and spontaneously release high quantities of granulysin. Am J Reprod Immunol. 2011;66(5):363-372.

52. Siewiera J, et al. Human cytomegalovirus infection elicits new decidual natural killer cell effector functions. PLoS Pathog. 2013;9(4):e1003257.

53. Chantakru $S$, et al. Contributions from self-renewal and trafficking to the uterine NK cell population of early pregnancy. J Immunol. 2002;168(1):22-28.

54. Male V, Hughes T, McClory S, Colucci F, Caligiuri MA, Moffett A. Immature NK cells, capable of producing IL-22, are present in human uterine mucosa. J Immunol. 2010;185(7):3913-3918.

55. Keskin DB, et al. TGFbeta promotes conversion of CD16+ peripheral blood NK cells into CD16- NK cells with similarities to decidual NK cells. Proc Natl Acad Sci U S A. 2007;104(9):3378-3383

56. Lynch L, Golden-Mason L, Eogan M, O’Herlihy C, O'Farrelly C. Cells with haematopoietic stem cell phenotype in adult human endometrium: relevance to infertility? Hum Reprod. 2007;22(4):919-926.

57. Vacca $\mathrm{P}$, et al. CD34+ hematopoietic precursors are present in human decidua and differentiate into natural killer cells upon interaction with stromal cells. Proc Natl Acad SciU S A. 2011;108(6):2402-2407.

58. Carlino C, et al. Recruitment of circulating NK cells through decidual tissues: a possible mechanism controlling NK cell accumulation in the uterus during early pregnancy. Blood. 2008;111(6):3108-3115

59. Hanna J, et al. CXCL12 expression by invasive trophoblasts induces the specific migration of CD16- human natural killer cells. Blood. 2003; 102(5):1569-1577.

60. Li M, et al. Fetal-derived adrenomedullin mediates the innate immune milieu of the placenta. J Clin Invest. 2013;123(6):2408-2420.

61. Manaster I, et al. Endometrial NK cells are special immature cells that await pregnancy. J Immunol. 2008;181(3):1869-1876

62 . Hanna J, et al. Decidual NK cells regulate key developmental processes at the human fetal-maternal interface. Nat Med. 2006;12(9):1065-1074.

63. Zhang J, Chen Z, Smith GN, Croy BA. Natural killer cell-triggered vascular transformation: maternal care before birth? Cell Mol Immunol. 2011;8(1):1-11.

64. Ashkar AA, Di Santo JP, Croy BA. Interferon gamma contributes to initiation of uterine vascular modification, decidual integrity, and uterine natural killer cell maturation during normal murine pregnancy. J Exp Med 2000;192(2):259-270.

65. Apps R, et al. Ex vivo functional responses to HLA-G differ between blood and decidual NK cells. Mol Hum Reprod. 2011;17(9):577-586.

66. Croy BA, van den Heuvel MJ, Borzychowski AM, Tayade C. Uterine natural killer cells: a specialized differentiation regulated by ovarian hormones. Immunol Rev. 2006;214:161-185.

67. Robson A, et al. Uterine natural killer cells initiate spiral artery remodeling in human pregnancy. FASEB J. 2012;26(12):4876-4885.

68. Kam EP, Gardner L, Loke YW, King A. The role of trophoblast in the physiological change in decidual spiral arteries. Hum Reprod. 1999;14(8):2131-2138.

69. Lash GE, et al. Expression of angiogenic growth factors by uterine natural killer cells during early pregnancy. J Leuk Biol. 2006;80(3):572-580.

70. Colucci F, Boulenouar S, Kieckbusch J, Moffett A. How does variability of immune system genes affect placentation? Placenta. 2011;32(8):539-545.

71. Parham P, Moffett A. Variable NK cell receptors and their MHC class I ligands in immunity, reproduction and human evolution. Nat Rev Immunol. 2013;13(2):133-144.

72. El Costa H, et al. Critical and differential roles of NKp46- and NKp30-activating receptors expressed by uterine NK cells in early pregnancy. J Immunol. 2008;181(5):3009-3017.

73. Vacca P, et al. Regulatory role of NKp44, NKp 46 , DNAM-1 and NKG2D receptors in the interaction between NK cells and trophoblast cells. Evidence for divergent functional profiles of decidual versus peripheral NK cells. Int Immunol. 2008;20(11):1395-1405

74. Hoglund P, Brodin P. Current perspectives of natural killer cell education by MHC class I molecules. Nat Rev Immunol. 2010;10(10):724-734.

75. Valiante NM, et al. Functionally and structurally distinct NK cell receptor repertoires in the peripheral blood of two human donors. Immunity. 1997; 7(6):739-751

76. Lightner A, Schust DJ, Chen YB, Barrier BF. The fetal allograft revisited: does the study of an ancient invertebrate species shed light on the role of natural killer cells at the maternal-fetal interface? Clin Dev Immunol. 2008;2008:631920

77. Cudkowicz G, Bennett M. Peculiar immunobiology of bone marrow allografts. I. Graft rejection by irradiated responder mice. J Exp Med 1971;134(1):83-102.

78. Kiessling R, Hochman PS, Haller O, Shearer GM, Wigzell $\mathrm{H}$, Cudkowicz $\mathrm{G}$. Evidence for a similar or common mechanism for natural killer cell activity and resistance to hemopoietic grafts. Eur Immunol. 1977;7(9):655-663.

79. Yu YY, Kumar V, Bennett M. Murine natural killer cells and marrow graft rejection. Annu Rev Immunol. 1992;10:189-213.

80. Ruggeri L, et al. Effectiveness of donor natural killer cell alloreactivity in mismatched hematopoietic transplants. Science. 2002;295(5562):2097-2100.

81. Karre K. Immunology. A perfect mismatch. Science. 2002;295(5562):2029-2031.

82. Sunderland CA, Naiem M, Mason DY, Redman CW,
Stirrat GM. The expression of major histocompatibility antigens by human chorionic villi. J Reprod Immunol. 1981;3(6):323-331.

83. Apps R, Murphy SP, Fernando R, Gardner L, Ahad T, Moffett A. Human leucocyte antigen (HLA) expression of primary trophoblast cells and placental cell lines, determined using single antigen beads to characterize allotype specificities of antiHLA antibodies. Immunology. 2009;127(1):26-39.

84. Marlin R, et al. Dynamic shift from CD85j/ILT-2 to NKG2D NK receptor expression pattern on human decidual NK during the first trimester of pregnancy. PLoS One. 2012;7(1):e30017.

85. Sharkey AM, et al. Killer Ig-like receptor expression in uterine NK cells is biased toward recognition of HLA-C and alters with gestational age. J Immunol. 2008;181(1):39-46.

86. Xiong S, et al. Maternal uterine NK cell-activating receptor KIR2DS1 enhances placentation. J Clin Invest. 2013;123(10):4264-4272.

87. Male V, Sharkey A, Masters L, Kennedy PR, Farrell LE, Moffett A. The effect of pregnancy on the uterine NK cell KIR repertoire. Eur J Immunol. 2011;41(10):3017-3027.

88. Madeja Z, et al. Paternal MHC expression on mouse trophoblast affects uterine vascularization and fetal growth. Proc Natl Acad Sci U S A. 2011; 108(10):4012-4017.

89. Kieckbusch J, Gaynor LM, Moffett A, Colucci F. MHC-dependent inhibition of uterine NK cells impedes fetal growth and decidual vascular remodelling. Nat Commun. 2013;5:3359.

90. Mallidi TV, Craig LE, Schloemann SR, Riley JK. Murine endometrial and decidual NK1.1+ natural killer cells display a B220+CD11c+ cell surface phenotype. Biol Reprod. 2009;81(2):310-318.

91. Yadi H, Burke S, Madeja Z, Hemberger M, Moffett A, Colucci F. Unique receptor repertoire in mouse uterine NK cells. JImmunol. 2008;181(9):6140-6147.

92. Chazara O, Xiong S, Moffett A. Maternal KIR and fetal HLA-C: a fine balance. J Lenk Biol. 2011; 90(4):703-716

93. Hiby SE, et al. Maternal activating KIRs protect against human reproductive failure mediated by fetal HLA-C2.J Clin Invest. 2010;120(11):4102-4110.

94. Hiby SE, Regan L, Lo W, Farrell L, Carrington M, Moffett A. Association of maternal killer-cell immunoglobulin-like receptors and parental HLA-C genotypes with recurrent miscarriage. Hum Reprod. 2008;23(4):972-976.

95. Hiby SE, et al. Combinations of maternal KIR and fetal HLA-C genes influence the risk of preeclampsia and reproductive success. J Exp Med 2004; 200(8):957-965

96. Moffett A, Regan L, Braude P. Natural killer cells, miscarriage, and infertility. BMJ. 2004; 329(7477):1283-1285.

97. Sher Fertility Clinics Centers for Reproductive Medicine. Causes for Infertility. Sher Fertility Web site. http://haveababy.com/causes-of-infertility/ causes-of-infertility-immune-factors/. Accessed March 17, 2014

98. Braverman IVF and Reproductive Immunology. Treatment for recurrent pregnancy loss. http:// www.preventmiscarriage.com/ReproductiveImmunology/Treatments.aspx. Accessed March 26, 2014.

99. Boomsma CM, Keay SD, Macklon NS. Peri-implantation glucocorticoid administration for assisted reproductive technology cycles. Cochrane Database Syst Rev. 2012;6:CD005996.

100. Kwak JY, Kwak FM, Ainbinder SW, Ruiz AM, Beer AE. Elevated peripheral blood natural killer cells are effectively downregulated by immunoglobulin $\mathrm{G}$ infusion in women with recurrent spontaneous abortions. Am J Reprod Immunol. 1996;35(4):363-369.

101.Human Fertilisation and Embriology Authority. Reproductive immunology - Natural killer cells - 
Fertility. HFEA Web site. http://www.hfea.gov.uk/ fertility-treatment-options-reproductive-immunology.html. Accessed March 17, 2014.

102. Katano K, Suzuki S, Ozaki Y, Suzumori N, Kitaori T, Sugiura-Ogasawara M. Peripheral natural killer cell activity as a predictor of recurrent pregnancy loss: a large cohort study. Fertil Steril. 2013;100(6):1629-1634.

103. Kuroda K, et al. Elevated periimplantation uterine natural killer cell density in human endometrium is associated with impaired corticosteroid signaling in decidualizing stromal cells. J Clin Endocrinol Metab. 2013;98(11):4429-4437.

104.Tang AW, Alfirevic Z, Turner MA, Drury JA, Small $\mathrm{R}$, Quenby S. A feasibility trial of screening women with idiopathic recurrent miscarriage for high uterine natural killer cell density and randomizing to prednisolone or placebo when pregnant. Hum Reprod. 2013;28(7):1743-1752.

105. Toth B, Wurfel W, Germeyer A, Hirv K, Makrigiannakis A, Strowitzki T. Disorders of implantation - are there diagnostic and therapeutic options? J Reprod Immunol. 2011;90(1):117-123.

106.Wurfel W, et al. High pregnancy rates with administration of granulocyte colony-stimu- lating factor in ART-patients with repetitive implantation failure and lacking killer-cell immunglobulin-like receptors. Hum Reprod. 2010; 25(8):2151-2152

107. Polanski LT, et al. Interventions to improve reproductive outcomes in women with elevated natural killer cells undergoing assisted reproduction techniques: a systematic review of literature. Hum Reprod. 2014;29(1):65-75.

108.Seshadri S, Sunkara SK. Natural killer cells in female infertility and recurrent miscarriage: a systematic review and meta-analysis [published online ahead of print November 27, 2013]. Hum Reprod Update. doi:10.1093/humupd/dmt056.

109. Moffett A, Hiby S. Influence of activating and inhibitory killer immunoglobulin-like receptors on predisposition to recurrent miscarriages. Hum Reprod. 2009;24(8):2048-2049.

110.The Fertility \& Gynaecology Academy. Immune Testing for Infertility. FGA Web site. http://www. fertility-academy.co.uk/recurrent-failure/immunetesting-for-infertility/. Accessed March 17, 2014.

111. Norman PJ, et al. Co-evolution of human leukocyte antigen (HLA) class I ligands with killer-cell immunoglobulin-like receptors (KIR) in a geneti- cally diverse population of sub-Saharan Africans. PLoS Genet. 2013;9(10):e1003938.

112. Hilton HG, et al. Mutation at positively selected positions in the binding site for HLA-C shows that KIR2DL1 is a more refined but less adaptable NK cell receptor than KIR2DL3. J Immunol. 2012; 189(3):1418-1430.

113. Wiggins DA, Main E. Outcomes of pregnancies achieved by donor egg in vitro fertilization - a comparison with standard in vitro fertilization pregnancies. Am J Obstet Gynecol. 2005;192(6):2002-2006.

114. Gasteiger G, et al. IL-2-dependent tuning of NK cell sensitivity for target cells is controlled by regulatory T cells. J Exp Med 2013;210(6):1167-1178.

115. Ghiringhelli F, et al. CD4+CD25+ regulatory T cells inhibit natural killer cell functions in a transforming growth factor- $\beta$-dependent manner. J Exp Med 2005;202(8):1075-1085.

116. Waggoner SN, Cornberg M, Selin LK, Welsh RM. Natural killer cells act as rheostats modulating antiviral T cells. Nature. 2012;481(7381):394-398.

117. Vacca P, et al. Crosstalk between decidual NK and CD14+ myelomonocytic cells results in induction of Tregs and immunosuppression. Proc Natl Acad Sci US A. 2010;107(26):11918-11923. 